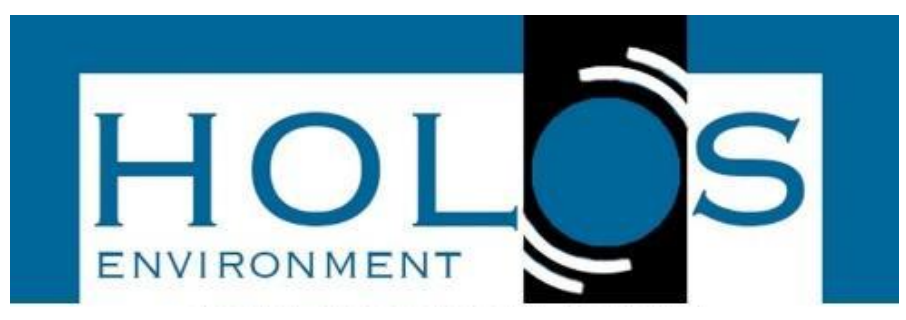

\title{
PROBLEMÁTICA DOS RESÍDUOS SÓLIDOS EM CANTEIROS DE OBRAS RESIDENCIAIS HORIZONTAIS NO INTERIOR PAULISTA: ESTUDO DE CASO
}

\section{PROBLEM OF SOLID WASTE IN HORIZONTAL RESIDENTIAL CONSTRUCTION SITE ON THE PAULISTA INTERIOR: CASE STUDY}

\author{
Eduarda Regina Carvalho'; Mateus Ricardo Batista da Silva1
}

Artigo recebido em: 21/07/2021 e aceito para publicação em: 25/11/2021.

DOI: http://doi.org/10.14295/holos.v21i3.12447

Resumo: A construção civil é responsável por grande parte dos resíduos sólidos produzidos nas áreas urbanas, fato este alarmante e extremamente preocupante, do ponto de vista do desenvolvimento sustentável. Neste trabalho, foi realizado um estudo de caso sobre Resíduos da Construção Civil, sua identificação, destinação e processamento, apontando possíveis falhas que podem ser prejudiciais ao meio ambiente. A pesquisa concentrou-se em regiões do interior do estado de São Paulo, nos municípios de Caconde e São José do Rio Pardo, em canteiros residenciais horizontais. Inicialmente, a abordagem foi exploratória e posteriormente, aplicou-se as metodologias de pesquisa: explicativa, experimental, estudo de campo e o método de diagnóstico, avaliando-se como o problema é abordado nos respectivos municípios. Constatou-se que a destinação dos resíduos ocorre sem a devida separação ou reciclagem, sendo o item, instalações provisórias no canteiro de obras, classificado como ruim e em grande parte, não atende aos requisitos legais para seu bom funcionamento, fato verificado em ambas as construções. Os municípios diferem em termos de legislação municipal, mas depositam os resíduos urbanos em um mesmo aterro, localizado em um terceiro município. Verificou-se que os procedimentos requerem maior atenção por parte das construtoras que, por sua vez, carecem de fiscalização por parte do poder público, o que gera grande preocupação quanto a gestão ambiental e o desenvolvimento sustentável nas localidades citadas.

Palavras-chave: Resíduos da Construção Civil. Descarte e Processamento. Sustentabilidade. Interior Paulista.

Abstract: Civil construction is responsible for a large part of the solid waste produced in urban areas, a fact that is alarming and extremely worrying, from the point of view of sustainable development. In this work, a case study was carried out on Civil Construction Waste, its identification, destination and processing, pointing out possible failures that could be harmful to the environment. The research focused on interior regions of the state of São

\footnotetext{
1 Universidade Paulista (UNIP), Instituto de Ciências Exatas e Tecnologia (ICET), São José do Rio Pardo, SP. E-mails: (carveduarda@gmail.com, mateusr.s.batista@gmail.com).
} 
Paulo, in the municipalities of Caconde and São José do Rio Pardo, in horizontal residential construction sites. Initially, the approach was exploratory and later, research methodologies were applied: explanatory, experimental, field study and the method of diagnosis, evaluating how the problem is approached in the respective cities. It was found that the disposal of waste occurs without proper separation or recycling, with the item, provisional installations at the construction site, classified as bad and, for the most part, does not meet the legal requirements for its proper functioning, a fact verified in both buildings. Municipalities differ in terms of municipal legislation, but they deposit urban waste in the same landfill, located in a third municipality. It was found that the procedures require greater attention on the part of the construction companies, which, in turn, lack inspection by the government, which generates great concern about environmental management and sustainable development in the aforementioned locations.

Keywords: Civil Construction Waste. Disposal and Processing. Sustainability. Interior of São Paulo.

\section{INTRODUÇÃO}

O desenvolvimento da sociedade embora necessário, ocorre de forma desenfreada e na maioria das vezes, não caminha em paralelo com a preservação ambiental e o desenvolvimento sustentável de forma ecoeficiente. A construção civil contempla esse desafio, sendo o setor que mais polui o meio ambiente (ROITMAN et al., 2015).

Reconhecida em larga escala como grande geradora de impactos ambientais, pela geração de resíduos, consumo e desperdício de água e de energia (SPADOTTO et al., 2011; ROITMAN et al., 2015; ALONSO, 2019; MATUTI, 2019 e LEAL, 2021), há anos, a contrução civil recebe críticas em relação aos desperdícios de matéria-prima e insumos, sendo grande consumidora de recursos naturais não renováveis (FERREIRA, 2013), onde a cadeia produtiva consome entre 20 e $50 \%$ dos recursos naturais de todo o planeta (BRASILEIRO e MATOS, 2015; LAMÔNICA et al., 2019).

Além disso, o setor o qual possui grande participação no Produto Interno Bruto (PIB) é responsável por representar cerca de $6,2 \%$ do PIB, no Brasil, faturando anualmente 1,1 trilhões de reais (SEBRAE, 2019), com participação expressiva na taxa de geração de poluentes, representando a maior fonte de geração dos Resíduos Sólidos Urbanos (RSU), (SCHMIDT e OSEBOLD, 2017).

De acordo com a ABELPRE - Associação Brasileira de Empresas de Limpeza Pública e Resíduos Especiais (2017) no Brasil, somente no ano de 2017, os municípios coletaram cerca de 45,1 milhões de toneladas de Resíduos da Construção Civil (RCC), 
considerando-se apenas os resíduos lançados ou abandonados em logradouros públicos (ABRELPE, 2017).

O Conselho Nacional do Meio Ambiente (CONAMA) em sua resolução 307/2002 define RCC como "os provenientes de construções, reformas, reparos e demolições de obras de construção civil, e os resultantes da preparação e da escavação de terrenos, tais como: tijolos, blocos cerâmicos, concreto em geral, solos, rochas, metais, resinas, colas, tintas, madeiras e compensados, argamassa, gesso, telhas, tubulações, fiação elétrica etc., comumente chamados de entulhos de obras, caliça ou metralha" (CONAMA, 2002; FERNANDES E MAFFESSONI, 2019; CIRELLI et al., 2021).

Nessa linha, também são considerados os denominados Resíduos da Construção e Demolição (RCD). Os RCD, popularmente conhecidos como entulho, são gerados pelo setor da construção civil em ampliações, reformas, novas construções, demolições, obras de infraestrutura e saneamento básico. O entulho é um resíduo diversificado onde se constitui restos de todos os materiais utilizados em uma construção (SALOMÃO et al., 2019). A denominação RCD é usada por que entulho é um termo amplo, que remete a ideia da natureza desses resíduos, provenientes da área da construção civil e das demolições (MATUTI, 2019).

Os RCD representam cerca de um total de 71,6 milhões de toneladas de resíduos urbanos, que corresponde a aproximadamente, $62 \%$ de todo o resíduo sólido gerado no Brasil (ABRELPE, 2017).

Também representam uma grande quantidade dos resíduos gerados internacionalmente (CORONADO et al., 2011). Segundo Kaluarachchi (2018), a maior parte dos resíduos gerados no mundo é originada da construção e da demolição de edifícios. De fato, os RCD têm impactado severamente o meio ambiente em escala mundial, uma vez que esses resíduos compõem de 10 a 30\% dos resíduos recebidos em aterros sanitários, causando preocupação de ordem pública, pois seu descarte inadequado ocasiona inúmeros problemas ambientais, prejudicando a saúde da população (FERNANDES, 2015; ONGKAMSUK et al. 2017; MATUTI, 2019).

Cerca de $90 \%$ destes resíduos gerados, podem ser reciclados e a sua reciclagem tem importância tanto financeira, quanto ambiental, pois alguns resíduos podem retornar à obra como matérias primas, não necessitando serem extraídos da natureza (LIMA \& LIMA, 2016).

A geração dos RCC e RCD interfere no meio físico, biótico e antrópico do local da construção, como consequência da falta de gestão de qualidade, sendo considerados como 
um problema mundial, comprovando a falta de organização e políticas relacionadas ao gerenciamento de obras (GLÓRIA et al., 2020). A incorporação desses resíduos na produção de materiais e elementos construtivos, por exemplo, reduz significativamente o consumo de energia e de matérias primas naturais, refletindo de forma direta na redução do custo final das construções (MALTA et al., 2013).

Devido as atividades realizadas durante a obra, monitorar e avaliar o consumo de energia, água e geração de resíduos nos canteiros de obras, são fatores primordiais, os quais viabilizam a identificação de falhas nos sistemas operacionais, contribuindo para uma gestão mais eficaz e eficiente (FROUFE et al., 2020).

No Brasil, grande parte dos municípios não possuem um sistema de captação e local para destinação adequada, elevando o índice de descarte ilegal para a faixa dos 10 a 47\%. Os locais mais afetados são terrenos baldios, beira de estradas e margens de cursos d'agua (GLÓRIA et al., 2020).

Ao abordar sobre o descarte de resíduos da construção é necessário, portanto, mencionar sobre gerenciamento, tanto em nível de gestão de materiais quanto gestão ambiental, logo, deve-se mencionar os "três erres" (Reduzir, Reciclar e Reaproveitar), uma vez que em uma construção, é possível encontrar diversos exemplos de materiais reaproveitáveis como madeiras e material primário (DINÂMICA AMBIENTAL 2014; SEBRAE, 2014; SALOMÃO et al, 2019).

A Política Nacional dos Resíduos Sólidos (PNRS), sancionada em 2010 e vigorando a partir de 2014, torna obrigatória a elaboração de Plano de Gerenciamento de Resíduos Sólidos - PGRS de empreendimentos considerados grandes geradores e/ou passíveis de licenciamento ambiental, contribuindo assim para o controle da geração, segregação, transporte, acondicionamento e destinação final (PNRS, 2010). A PNRS, aponta ainda como prioridade a não geração, reutilização, reciclagem e tratamento dos resíduos, além do despejo ambiental adequado e determina que quem gera os resíduos que não são transportados, tratados, armazenados e descartados de acordo com a PNRS, terá que responder nas esferas civil, penal e administrativa (PNRS, 2010).

Uma questão importante refere-se aos locais onde serão depositados esses resíduos, principalmente nos grandes centros urbanos, onde as áreas são escassas e 0 volume gerado é considerável o que, consequentemente, acaba ocasionando transtornos à população, além de requerer investimentos elevados para adequar o processo à legislação (LIMA et al., 2021). 
Muitos municípios ainda não apresentam estrutura suficiente para a destinação de todos os tipos de resíduos gerados nas obras, o que não invalida as ações para segregação e descarte adequados, fato este que impõe uma forte mudança na cultura hoje estabelecida, sendo necessária uma alteração nos sistemas construtivos existentes. Para que isto aconteça, é preciso reestudar os processos, visando estabelecer formas de evitar a geração de resíduos. Além de reduzir, reutilizar e reciclar é preciso, antes de tudo, repensar (FIEB, 2021).

Diante do exposto, o presente trabalho aborda a questão dos resíduos sólidos da construção, gerados em regiões interioranas do estado de São Paulo, considerando-se canteiro de obra horizontal residencial, através da implantação de uma metodologia de pesquisa exporatória/quantitativa, obtendo-se uma leitura de paisagem associada ao descarte e suas implicações, em cidades do interior do estado, onde pesquisas científicas são escassas.

\section{MATERIAL E MÉTODOS}

\section{1 Áreas de Estudo}

\subsubsection{Características da cidade de Caconde-SP.}

A cidade de Caconde é um dos 15 municípios paulistas considerados estâncias climáticas pelo Estado de São Paulo, por cumprirem determinados pré-requisitos definidos por Lei Estadual. Tal status garante a esse município uma verba maior por parte do Estado para a promoção do turismo regional. Também, o município adquire o direito de agregar junto a seu nome o título de Estância Climática, termo pelo qual passa a ser designado tanto pelo expediente municipal oficial quanto pelas referências estaduais. Localiza-se a

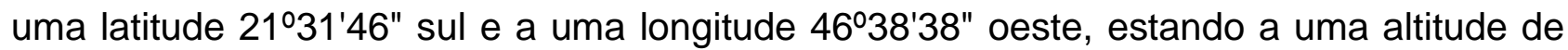
860 metros em relação ao nível do mar (SPCIDADES, 2021a).

Segundo o IBGE, Caconde/SP apresenta área da unidade territorial de $468.214 \mathrm{~km}^{2}$, onde $68.1 \%$ dos domicílios contêm esgotamento sanitário adequado, $83.8 \%$ dos domicílios urbanos são vias públicas com arborização, $59.2 \%$ dos domicílios urbanos em vias públicas apresentam bueiros, calçadas, pavimentação e meio-fio (IBGE, 2021). Com 18.854 
habitantes, apresenta uma densidade demográfica de aproximadamente $40.3 \mathrm{hab} / \mathrm{km}^{2}$ (IBGE Cidades 2010).

\subsubsection{Características da cidade de São José do Rio Pardo-SP.}

São José do Rio Pardo, é um município brasileiro do estado de São Paulo. Localizase a uma latitude 21035'44" sul e a uma longitude 46-53'19" oeste, estando a uma altitude média de 676 metros (SPCIDADE, 2021b). Segundo o IBGE, apresenta área da unidade territorial de $419,684 \mathrm{~km}^{2}$ onde $90.8 \%$ dos domicílios contêm esgotamento sanitário adequado e $95.5 \%$ dos domicílios urbanos são vias públicas com arborização. Cerca de $61.2 \%$ dos domicílios urbanos apresentam bueiros, calçadas, pavimentação e meio-fio, (IBGE, 2021). De acordo com o último censo, a população local é da ordem de 51.900 habitantes, com uma densidade demográfica de aproximadamente $123.81 \mathrm{hab} / \mathrm{km}^{2}$ (IBGE Cidades, 2010).

A Figura 1, ilustra o mapa de localização das cidades. A distância entre os municípios, é da ordem de $26.50 \mathrm{~km}$.

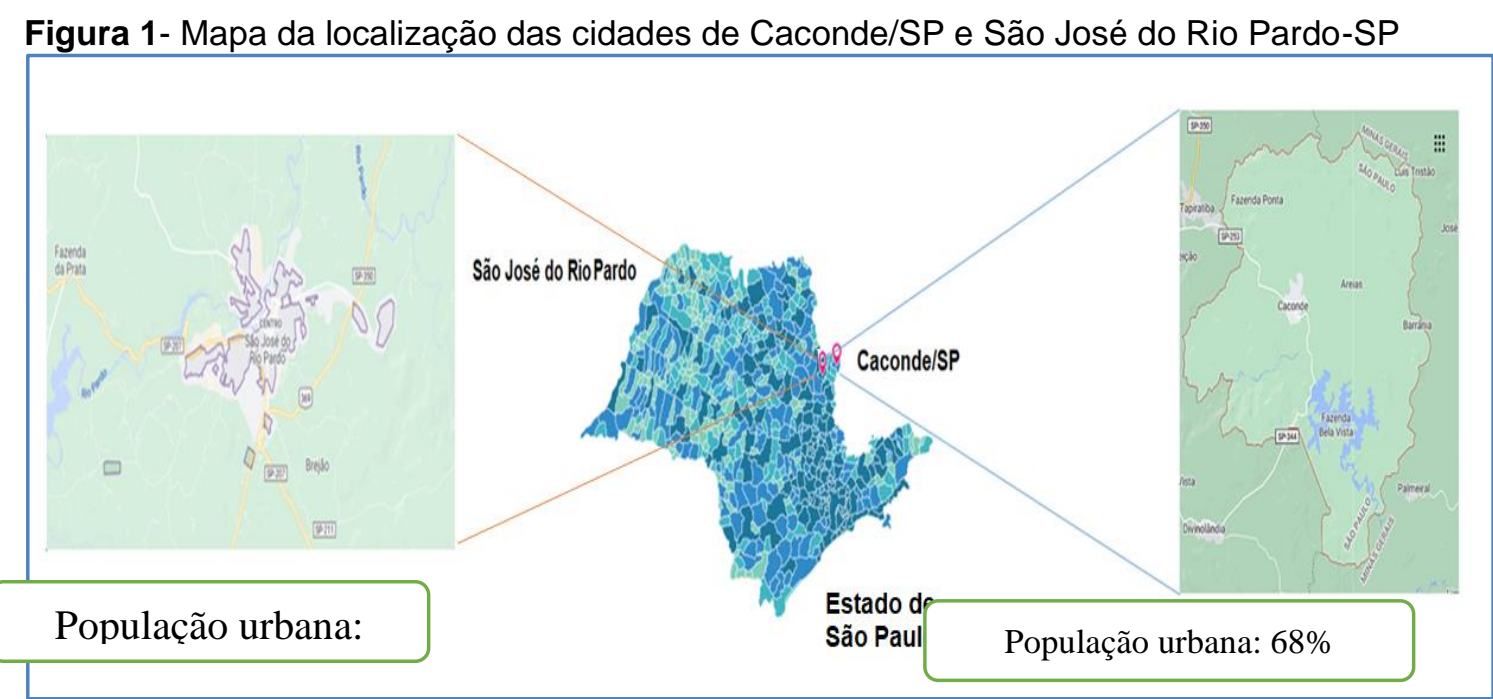

Fonte: Adaptado de IBGE Cidades (2010) e Google Maps.

\subsection{Caracterização dos canteiros de obras analisados}

As obras selecionadas são obras horizontais residências unifamiliares térreas, porém, suas identificações foram mantidas em sigilo, mediante solicitação dos gestores 
vinculados às construtoras. O quadro 1 a seguir, especifica as características de cada obra analisada.

A escolha das obras nas mesmas fases executivas foi realizada de maneira que pudesse ser verificada a influência da etapa da obra na qualidade dos canteiros. Essa mesma filosofia foi utilizada na escolha quanto ao tipo de obra, pois é sabido que a dinâmica de uma obra vertical difere de uma obra horizontal, principalmente do ponto de vista das etapas de execução.

Quadro1- Características de cada obra analisada.

\begin{tabular}{|c|c|c|c|c|}
\hline Cidade & $\begin{array}{c}\text { Identificação da } \\
\text { Construtora }\end{array}$ & $\begin{array}{c}\text { Tipo de } \\
\text { Obra }\end{array}$ & $\begin{array}{c}\text { Processo } \\
\text { produtivo }\end{array}$ & Fase da Obra \\
\hline $\begin{array}{c}\text { São José do } \\
\text { Rio Pardo-SP }\end{array}$ & Construtora A & $\begin{array}{c}\text { Residencial } \\
\text { horizontal }\end{array}$ & $\begin{array}{c}\text { Alvenaria } \\
\text { Convencional }\end{array}$ & Intermediária \\
\hline Caconde-SP & Contrutora B & $\begin{array}{c}\text { Residencial } \\
\text { horizontal }\end{array}$ & $\begin{array}{c}\text { Alvenaria } \\
\text { Convencional }\end{array}$ & Intermediária \\
\hline & \multicolumn{3}{|l}{} \\
\hline
\end{tabular}

Fonte: Autores

\subsection{Instrumentos de medição e tratamento dos dados}

A coleta de dados foi realizada com o auxílio do instrumento de medição denominado trena ou fita métrica com extensão de trinta metros no total e material de fibra vidro. A trena permite a medição em qualquer direção sendo ideal para coleta de dados em área quadradas e cúbicas. Para o tratamento dos dados, foram utilizados os softwares Excel e o Origin (versão livre).

\subsection{Metodologia de Análise dos dados}

Para a realização do trabalho foram utilizados métodos exploratório/quantitativo, em três etapas, as quais estão especificadas no fluxograma a seguir (Figura 2). 
Figura 2 - Fluxograma da metodologia experimental utilizada neste trabalho

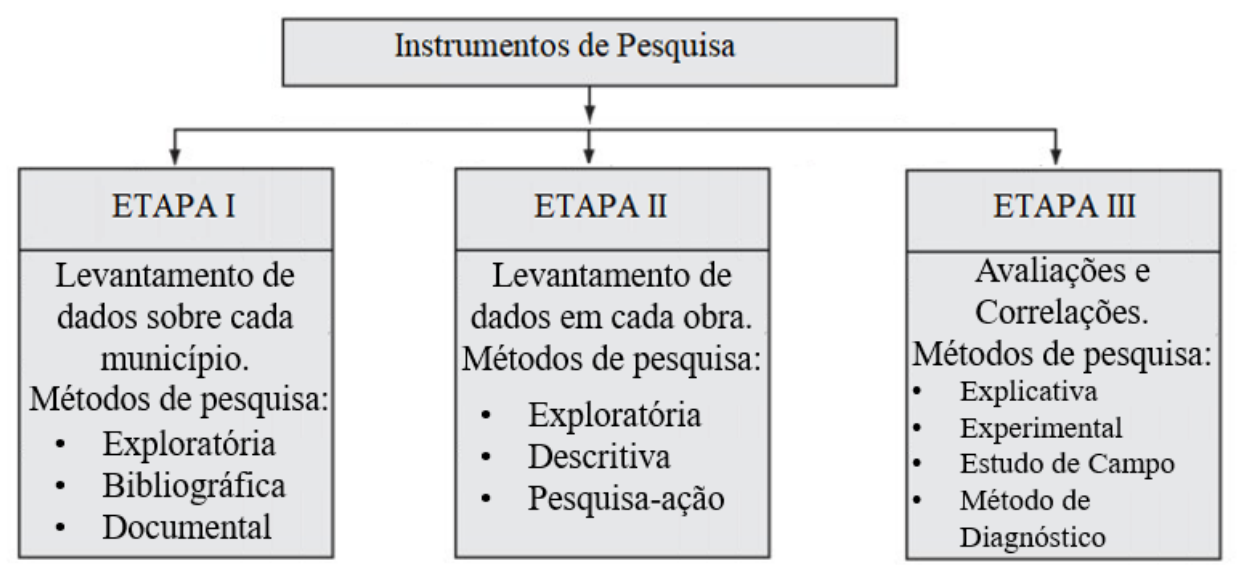

Fonte: Autores

\section{- Instrumentos de pesquisa}

$\mathrm{Na}$ fase inicial da pesquisa considerou-se a pesquisa exploratória. Dada a importância do tema, esse método de pesquisa proporciona maior familiaridade com o problema. A contribuição teórica tem como foco a compreensão do tema sob investigação e intervenção, por meio da identificação, criação e aplicação de conceitos, tornando-os acessíveis e compilados em um único material. Adotou-se o método de pesquisa-ação a qual assume, além de um caráter descritivo, também o prescritivo, onde os participantes representativos da situação ou do problema estão envolvidos de modo cooperativo ou participativo (GIL, 2008), que no caso seriam os gestores das obras, mestres de obras, funcionários e representantes das construtoras.

Para a condução dos métodos de levantamento dados, foi necessária a elaboração de um instrumento formal de coleta, considerando-se os seguintes delineamentos: a) levantamento de dados sobre os municípios; b) levantamento de dados quanto a geração e disposição dos resíduos sólidos, bem como as leis municipais e diretrizes adotadas; c) análise das obras e, d) correlação das informações obtidas e avaliações. A seguir, são descritas cada uma das etapas efetuadas, especificando as metodologias utilizadas.

Etapa I- Levantamento de dados sobre cada município

Os dados coletados, referentes às informações sobre cada município, foram obtidos junto a órgãos locais como prefeituras e órgãos governamentais, via pesquisas eletrônicas, que monitoram e possuem registros específicos de cada localidade, com levantamentos realizados por anos e de maneira sazonal. Mapeando-se e avaliando todas as informações, foi possível apurar com detalhes específicos as diretrizes nos 
diferentes municípios. Para essa coleta de dados, foram aplicados os métodos de pesquisas: exploratória, bibliográfica e documental.

Etapa II- Levantamento de dados nas obras

Objetivando levantar informações sobre os RCC, nas diferentes localidades, foram adotadas as metodologias de pesquisa exploratória, descritiva e pesquisa-ação, visando obter a leitura de paisagem urbana quanto a geração dos RCC. Foram realizadas estimativas de acordo com os resultados, bem como estudos estatísticos referentes as amostragens.

\section{Etapa III - Avaliações e Correlações}

Nessa etapa, foram apresentados resultados numéricos e gráficos. Também foram aplicados nessa etapa, os seguintes métodos de pesquisa: (a) Pesquisa Explicativa: permitiu identificar os fatores que determinam ou que contribuem para a ocorrência de determinada situação ou fenômeno; (b) Pesquisa Experimental: selecionando as variáveis capazes de influenciar determinada postura, foi possível definir as formas de controle e de observação dos efeitos; (c) Estudo de Campo: procurou o aprofundamento quanto a realidade de cada município. Sendo basicamente realizada por meio da observação direta das atividades do grupo estudado e da interpretação de dados, para captar as explicações e interpretações que ocorrem naquela realidade e, (d) Método de Diagnóstico: consiste na aplicação de uma lista de verificação (check-list) padronizada. O método utilizado neste trabalho foi o desenvolvido por Saurin e Formoso (2006), para o Programa de Tecnologia da Habitação.

Saurin e Formoso (2006), desenvolveram um conjunto de métodos e técnicas adequados para a gestão da Qualidade, às peculiaridades das empresas de construção civil, particularmente àquelas de pequeno porte, visando elevação dos níveis de qualidade e produtividade do setor da construção.

A aplicação de um check-list foi realizada in loco durante as visitas às obras analisadas. A mesma contempla mais de 120 itens para verificação distribuídos em três grupos: instalações provisórias (Grupo 1), segurança no trabalho (Grupo 2) e sistema de movimentação e armazenamento de materiais (Grupo 3). Nesse processo, cada item da lista de verificação, de qualquer grupo, possui valor igual a 1 ponto. $O$ item recebe o ponto caso esteja assinalada a opção "sim". Na lista de verificação, ao final de cada grupo, são 
anotados os pontos obtidos (PO), os pontos possíveis (PP) e o índice do grupo (lg), que é dado pela Equação (1).

$$
\operatorname{Ig}=\left(\frac{P O}{P P}\right) * 10
$$

Quanto a nota global do canteiro, calcula-se a mesma fazendo a média aritmética das notas dos três grupos. Embora esta nota possa ser calculada, seu significado para a análise do desempenho do canteiro é secundário, se comparado ao significado das notas dos grupos. As notas dos grupos são mais úteis por agregarem somente o desempenho de elementos do canteiro semelhantes, devendo, por isso, serem priorizadas na comparação entre diferentes sistemas. Os pontos obtidos correspondem ao total de itens com avaliação positiva "sim", enquanto os pontos possíveis correspondem ao total de itens com avaliação positiva ou negativa, ou seja, o total de itens que puderam ser analisados. Os itens que não puderam passar por análise, por qualquer motivo, têm a marcação na coluna "não se aplica" e, portanto, não são considerados como pontos possíveis. Esse método permite a comparação de diferentes obras e empresas (SAURIN E FORMOSO, 2006).

O Ministério do Trabalho e Emprego (BRASIL, 2003), possui um sistema de classificação dos índices conforme mostrado no Tabela 1, sendo esta metodologia também adotada no presente estudo, onde as notas obtidas foram analisadas de acordo com esse procedimento.

Tabela 1- Sistema de classificação para o canteiro de obras segundo o Ministério do Trabalho

\begin{tabular}{cc}
\hline Pontuação & Classificação \\
\hline $0,00-2,00$ & Péssimo \\
$2,01-4,00$ & Ruim \\
$4,01-6,00$ & Regular \\
$6,01-8,00$ & Bom \\
$8,01-10,00$ & Ótimo \\
\hline
\end{tabular}

Fonte: Brasil (2003).

De acordo com o Tabela 1, a classificação "Péssimo" é atribuída a canteiros de obras em total desacordo com as normas regulamentadoras do trabalho, sendo necessária adequação as mesmas para que a obra possa continuar em funcionamento. A classificação "Ruim" é atribuída aos canteiros de obras que apresentam a maioria dos seus itens em desacordo com as normas regulamentadoras do trabalho, sendo necessário também adequação as mesmas, para manter o funcionamento da obra. Nas classificações 
"Regular", "Bom" e "Ótimo", a maioria dos itens do canteiro atendem aos requisitos mínimos das normas regulamentadores do trabalho, não acarretando em paralisações nas obras, sendo a classificação atribuída de acordo com o maior ou menor percentual de itens em acordo com os padrões mínimos para funcionamento da obra.

\section{RESULTADOS E DISCUSSÃO}

\subsection{Levantamento de dados sobre cada município}

De acordo com o Tribunal de Contas do Estado de São Paulo, Caconde/SP e São José do Rio Pardo/SP, não apresentam: depósito específico para resíduos da construção civil (bota fora), área para resíduos gerados no serviço de saúde, aterro industrial e/ou lixão a céu aberto. Ambas as cidades dispõem os resíduos urbanos no Aterro Sanitário (Unidade de Destinação dos Resíduos Sólidos), localizado em um terceiro município, na cidade de Tapiratiba conforme, figura 3.

Figura 3 - Aterro Sanitário utilizado para deposição de resíduos sólidos tanto para a cidade de Caconde-SP, quanto para a cidade de São José do Rio Pardo-SP

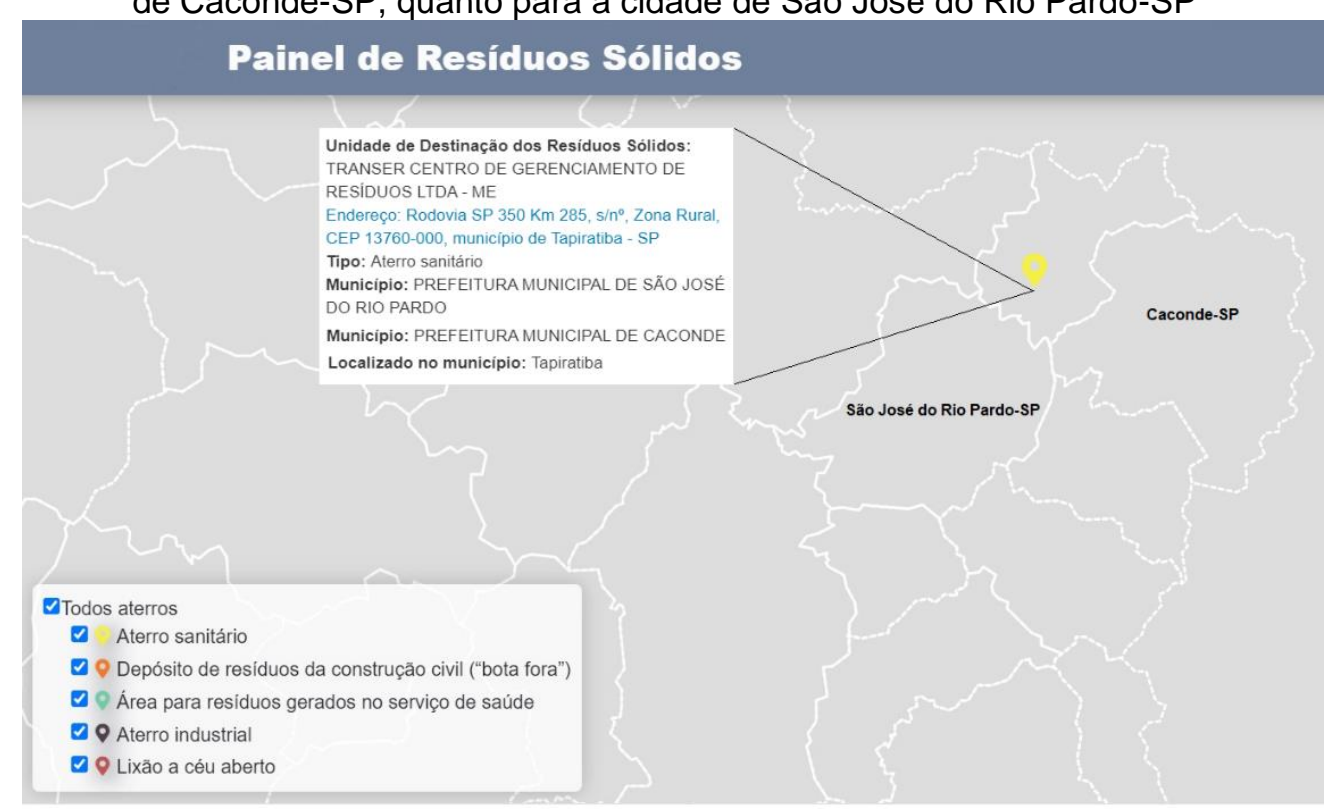

Fonte: Adaptado de Painel TCE (2021).

A distância entre os municípios e o Aterro Sanitário corresponde a 17 min (14,2km), considerando-se o trajeto mais rápido, com trânsito normal para a cidade de Caconde/SP e, para a cidade de São Jose do Rio Pardo/SP, considerando-se as mesmas condições de trânsito, é de 27 min, ou seja, em torno de 29,1km (GOOGLEMAPS, 2021). 
Caconde/SP não possui uma legislação municipal específica, a cerca da destinação dos resíduos sólidos. Apresenta um projeto de Lei № 011/2019 de 03/06/19, o qual dispõe sobre a aprovação da revisão e atualização do Plano de Saneamento Básico do Município e dá outras providências em relação aos resíduos sólidos como um todo. Quanto aos resíduos sólidos da construção civil, a cidade também não apresenta uma lei municipal sobre o tema (PROJETODELEI, 2019).

Segundo informações levantadas, três empresas fornecem o trabalho de "cata entulho" na cidade, com a locação de caçambas para o colhimento de entulhos da construção, nas obras residenciais. Os dados referentes à quantidade média, em caçambas, gerada por mês desta tipologia de resíduos, não foram fornecidos e a Prefeitura do município não possui um plano de controle e levantamento de tais informações. A cidade não apresenta um Programa Municipal de Gerenciamento de Resíduos e além disso, as construtoras que atendem às construções populares, com financiamentos da Caixa Econômica, por exemplo, possuem o próprio serviço de caçambas para a coleta dos entulhos, mas, também não há registros junto a Prefeitura, sobre a quantidade de entulhos coletados por essas empreiteiras.

São José do Rio Pardo, por sua vez, promulgou em agosto de 2010 a Lei de no 12.305/2010 que institui a Política Nacional de Resíduos Sólidos, regulamentada pelo Decreto no 7.404, de 23 de dezembro de 2010, os quais instituíram o PNRS, abrangendo o seu acondicionamento, armazenamento, coleta, transporte, destinação final e define que a responsabilidade pela coleta desse tipo de resíduo bem como a disposição final é de responsabilidade do gerador. A Lei $\mathrm{n}^{0}$ 2.153, de 8 de setembro de 1997, do município, dispõe sobre a coleta e remoção de RCD de imóveis. O projeto de Lei ํo 3.351 , de 26 de maio de 2009, dispõe sobre a coleta e remoção dos RCD do município e regulamenta o uso de caçambas, revogando a Lei ํㅜㄴ.589, de 05 de maio de 2002, (GEOMA AMBIENTAL, 2016).

De acordo com a resolução CONAMA o 307 de julho de 2002 esta, alterada pela Resolução 348/2004, a cerca da classificação dos RCC, estabelece a responsabilidade pelo gerenciamento do resíduo para o gerador e prevê que este realize a segregação dos resíduos em diferentes classes, bem como os destine para a reciclagem ou disposição final ambientalmente adequada (CONAMA, 2002).

Uma vez que o entulho, engloba resíduos de demolições e restos de obras, solos de escavações etc., é geralmente um material inerte passível de reaproveitamento. Se o resíduo pertence ao gerador, cabe a ele destinar de forma correta e a responder pelo 
descarte irregular. Somente o gerador pode contratar o destinatário do entulho e é assim que acontece, caso contrário, o problema é passado para frente, numa escala perniciosa e criminosa sem fim (TORRES, 2020).

O município também possui o Programa Municipal de Gerenciamento de Resíduos da Construção Civil - PROMGER instituído pela Lei nº 3381/2009. O Programa define, no Art. $2^{\circ}$, Inciso II da Lei Municipal, que pequeno gerador de RCC é pessoa física ou jurídica, pública ou privada, que gere até $2,5 \mathrm{~m}^{3}$ /dia de resíduos da construção civil, bem como as responsabilidades do pequeno gerador e da Prefeitura. O município ainda possui outras duas legislações que abrangem a regulamentação dos RCC gerados sendo essas: a Lei no 2303/1999, que no Art. 2ํaltera o Art. 68 do Código de Obras, referente ao valor das multas; e a Lei no 4.472/2015, que em seu Art. 1ํㅡ, altera o Art. 4ํ da Lei no 3.351/2009, acrescentando o Parágrafo 6, que estabelece multa de 1 (uma) UFM para empresa prestadora de serviço de coleta de RCC que durante o transporte, tiver resíduos derrubados em vias públicas (GEOMA AMBIENTAL, 2016).

Segundo o PROMGER, a quantidade média, em caçambas, gerada por mês desta tipologia de resíduos é da ordem de 590 caçambas por mês, de $3 \mathrm{~m}^{3}$ cada, totalizando a média de 2.185,95 ton. /Mês, conforme tabela 2. O setor é explorado por duas empresas particulares: a Kolentulho - Coleta de Entulhos e a São Bento Locações (GEOMA AMBIENTAL, 2016).

Tabela 2 - Quantidade média de caçambas coletadas por mês, na Cidade de São José do Rio Pardo

\begin{tabular}{lc}
\multicolumn{1}{c}{ Empo Pardo } & Quantidade média/mês \\
\hline São Bento Locações & 200 \\
Kolentulho & 390 \\
Total & 590 \\
\hline
\end{tabular}

Fonte: Adaptado de (GEOMA AMBIENTAL, 2016).

O município ainda não exige o plano de RCC para grandes geradores, nem o prevê em legislações municipais, mesmo este sendo definido no PNRS, Art. 20, inciso III e previsto na Resolução CONAMA 307/2002, em seu Art. 8ํ․ Além disso, o município também não realiza acompanhamento do Controle de Transporte de Resíduos (CTR), documento emitido pelo transportador de resíduos que fornece informações sobre: gerador, origem, quantidade e descrição dos resíduos e seu destino, conforme a NBR 15.113:2004.

Para os pequenos geradores, os quais geram até $2,5 \mathrm{~m}^{3} /$ dia de resíduos da construção civil, os procedimentos a serem seguidos são os previstos na Lei Municipal no 
3.381/2009, instituído no PROMGER, nos Art. 4ํㅜ 6ํㅡ e 7ํ. Para a coleta de resíduos da construção civil dos pequenos geradores, a Prefeitura cobra o valor de $R \$ 22,53 \mathrm{reais} / \mathrm{m}^{3}$. A destinação final dos RCC segundo informações contidas no PROMGER do município, segue as normas técnicas NBR 15.112; NBR 13.113; NBR 15.114; NBR 15.115 e NBR 15.116, (GEOMA AMBIENTAL, 2016).

\subsection{Levantamento de dados nas obras analisadas}

Obra na cidade de Caconde/SP

$\mathrm{Na}$ obra analisada na cidade de Caconde/SP, foram efetuadas cinco visitas. O período analisado foi de um mês corrido, com início ao dia 20 de outubro de 2020 e término à 20 de novembro de 2020. A tabela 3 , a seguir, mostra os valores de RCC obtidos para esta obra.

Tabela 3 - Dados coletados na obra 01, cidade de Caconde-SP

\begin{tabular}{ccc}
\hline & Visita & Total de Resíduos Gerados $\mathbf{~ M}^{\mathbf{3}} \mathbf{)}$ \\
\hline & Visita 01 & 4 \\
& Visita 02 & 8 \\
& Visita 03 & 1 \\
& Visita 04 & 6 \\
& Visita 05 & 3 \\
Total & $\mathbf{0 5}$ & $\mathbf{2 2} \mathbf{~ m}^{\mathbf{3}}$ \\
\hline
\end{tabular}

De acordo com a Tabela 3, os volumes de RCC gerados, apresentaram variação dependendo da época da visita, considerando-se a fase intermediária da obra, contabilizando um total de $22 \mathrm{~m}^{3}$ no período analisado. Para fins comparativos, por exemplo, para se estocar todo esse resíduo seria necessária uma gleba de terra de seção quadrada cujos lados sejam aproximadamente $5 \mathrm{~m} \times 4 \mathrm{~m}$, o que corresponde a uma área de terra insuficiente para construções, mas suficiente para o plantio e/ou, por exemplo, a elaboração de uma horta orgânica.

As figuras $4 \mathrm{a}$ e $4 \mathrm{~b}$, ilustram os resíduos encontrados na obra em questão, onde foi constatado que os RCC de imóveis, não têm destinação específica, sendo descartados de forma incorreta pelas margens de rodovias e estradas. 
Figura 4 - Em (a) Resíduos observados; (b) Resíduos de pedra brita, concreto e outros, observados na referida obra

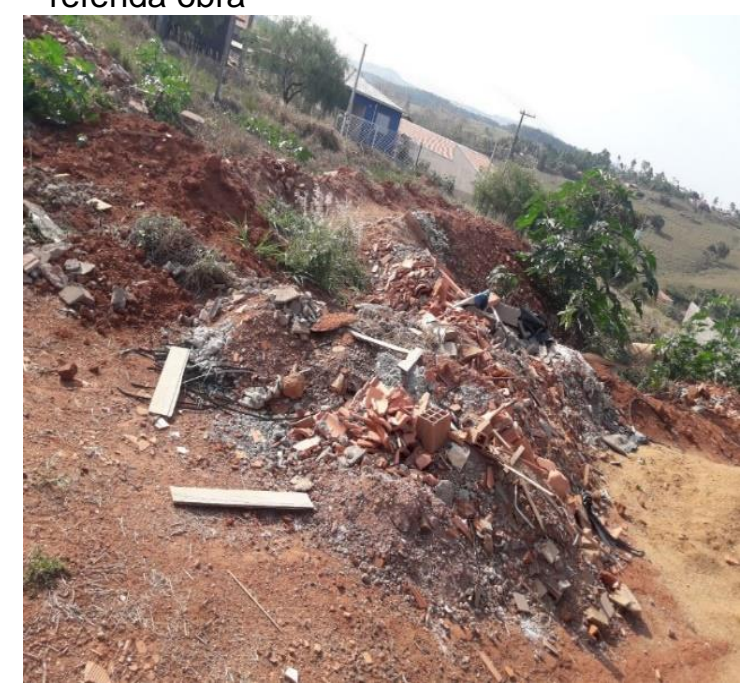

(a)

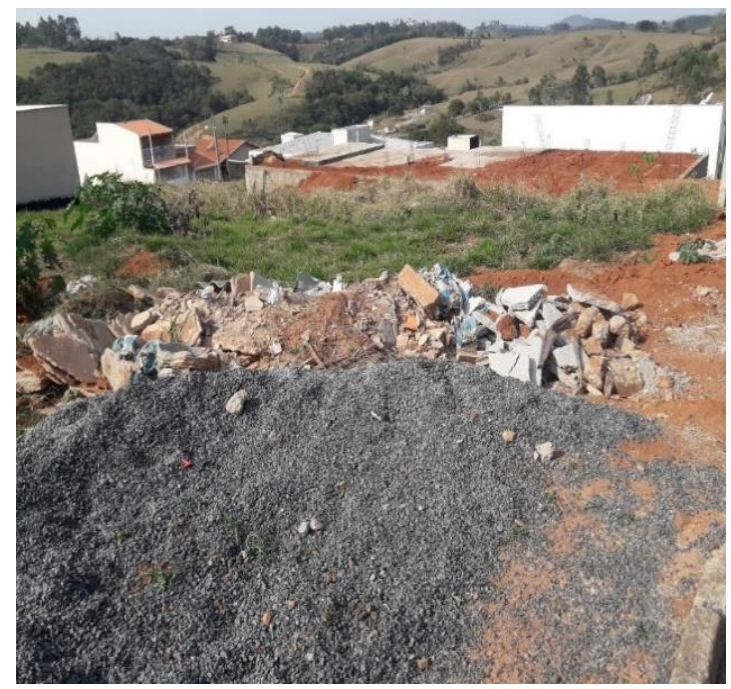

(b)

Fonte: Autores.

$\mathrm{Na}$ Figura 4a observam-se diferentes tipos de materiais tais como restos de alvenaria, madeiramento, concreto, areia e outros materiais de composição distintas, descartados sem nenhum tipo de separação ou distinção de resíduos, bem como não acondicionados em caçambas. Certamente uma separação adequada e a especificação de possível reaproveitamento, dos diferentes materiais, seriam os procedimentos mais adequados e recomendados. Na Figura 4b, observa-se os resquícios dos resíduos de demolição e material para futuras construções, estocados sem qualquer separação e em extrema proximidade, sem distinção de descarte e acondicionados em local não apropriado.

Segundo informações obtidas, no Bairro São João (zona rural) do município, havia uma usina particular, que separava e encaminhava os entulhos para reciclagem. Entretanto a mesma não se encontra em funcionamento por falta de recursos, embora tenha os vários aparatos necessários para efetuar a operação. O ideal seria essa usina voltar a funcionar, talvez com incentivos da Prefeitura, ou que a própria Prefeitura adquira uma usina de reciclagem de entulho da construção civil, padronizando o processo em conformidade com a legislação vigente.

O gráfico 1, ilustra a variação de resíduos encontrados no canteiro de acordo com as visitas periódicas efetuadas, onde observa-se alternância nos volumes de RCC gerados na fase intermediária da obra. 
Gráfico 1- Comparação entre as diferentes vsitas e quantidade de resíduos gerados, na obra na cidade de Caconde/SP

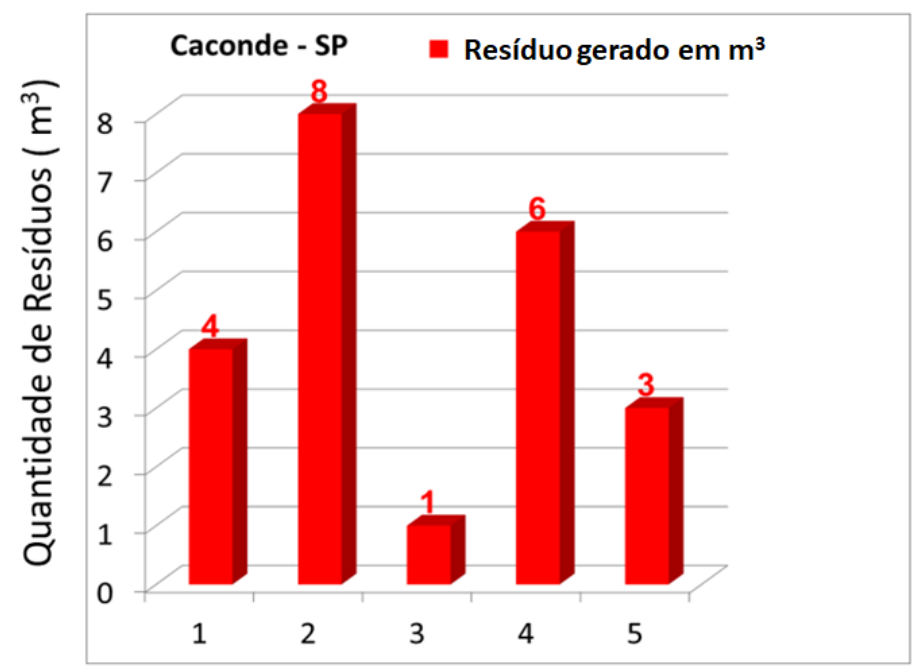

Número de visitas

De acordo com os dados do gráfico 1, a alternância observada está reacionada ao período em que se encontrava a obra, e mesmo nessas condições, em nenhum momento observou-se o gerenciamento adequado dos resíduos formados. Constatou-se na primeira visita cerca de $4 m^{3}$ de resíduos gerados, seguido por $8 m^{3}$, na segunda visita. Na sequência foram observados $1 \mathrm{~m}^{3}, 6 \mathrm{~m}^{3}$ e $3 \mathrm{~m}^{3}$, referentes à terceira, quarta e quinta visita, respectivamente.

O acúmulo de resíduos sem separação quanto ao tipo, sem gerenciamento e dispostos no terreno sem qualquer cuidado, afeta diretamente o entorno, prejudicando e ocasionando dessa forma, impactos negativos significativos para o meio ambiente e para a população circundante.

Além disso, o volume diferenciado de resíduos gerados em cada etapa da construção, constitui em uma problemática quanto ao gerenciamento da obra. Como não há um planejamento ao longo da execução das etapas como separação, destinação e descarte adequados, a obra se torna problemática necessitando de ajustes e alterações quanto aos procedimentos.

Para um gerenciamento adequado, a empreiteira poderia adotar processos eficientes desde o planejamento até a execução, no sentido da escolha dos materiais produzidos de forma ambientalmente responsável, da preocupação em reduzir o consumo excessivo de recursos naturais e, principalmente quanto ao despejo dos RCC, por exemplo, contratando empresas devidamente registradas pelo órgão fiscalizador para o transporte, destinação e descarte corretos. Para tanto, a documentação e o registro das atividades inerentes ao gerenciamento dos resíduos passam a ser fundamentais (NAGALLI, 2014), 
onde o planejamento das atividades visando o desenvolvimento sustentável, se tornam ações imprescindíveis de forma a minimizar os impactos ambientais.

Obra na cidade de São José do Rio Pardo/SP

Na obra na cidade de São José do Rio Pardo/SP, também foram realizadas um total de cinco visitas com datas escolhidas ao acaso, na fase intermediária da obra. O período analisado foi de um mês corrido com início ao dia 18 de setembro de 2020 a 18 de outubro de 2020. A tabela 4 a seguir, mostra os valores obtidos para a obra.

Tabela 4 - Dados coletados na obra 02, cidade de São José do Rio Pardo-SP.

\begin{tabular}{lcc}
\hline & Visita & Total de Resíduos Gerados $\left(\mathbf{M}^{3}\right)$ \\
\hline & Visita 01 & 6 \\
Visita 02 & 8 \\
Visita 03 & 4 \\
Visita 04 & 11 \\
& Visita 05 & 2 \\
Total & $\mathbf{0 5}$ & $\mathbf{3 1} \mathbf{~ m}^{3}$ \\
\hline
\end{tabular}

De acordo com a Tabela 4, observa-se volumes variados de resíduos sólidos gerados, contabilizando um total de $31 \mathrm{~m}^{3}$ no período analisado. Para fins comparativos, para se estocar todo esse resíduo seria necessária uma gleba de terra de seção quadrada cujos lados sejam aproximadamente $10 \mathrm{~m} \times 3 \mathrm{~m}$, o que corresponde a uma área de terra equiparando à um terreno suficientemente amplo para a construção de uma casa popular.

As figuras $5 \mathrm{a}$ e $5 \mathrm{~b}$ a seguir, ilustram os resíduos encontrados na obra. Na figura $5 \mathrm{a}$ é possível observar os restos de entulho onde se concentram diferentes resíduos de materiais tais como: cimento, areia, concreto, embalagens de papel, madeira etc., sem qualquer tipo de separação para o descarte dequado, sendo todo o resíduo gerado, amontoado em caçambas. Na figura 5b, observa-se os resíduos de madeiramento, gerados na respectiva obra, onde estes estão prontos para o descarte, espalhados pelo canteiro e não acondicionados em caçambas. É possível observar que estes resíduos, são totalmente apropriados para o reaproveitamento de forma sustentável. 
Figura 5 - (a) Caçamba para a coleta de entulho; (b) Resíduos de madeiramento gerados na respectiva construção.

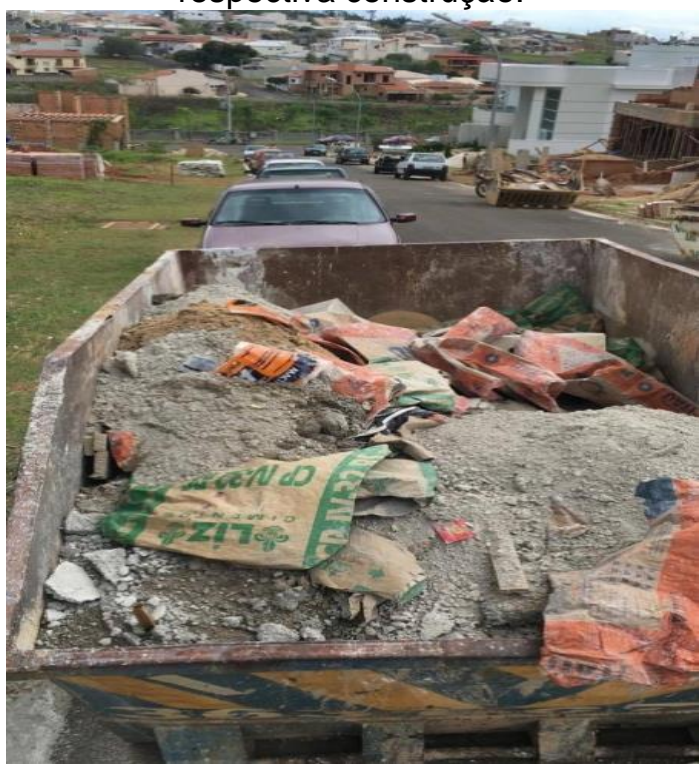

(a)

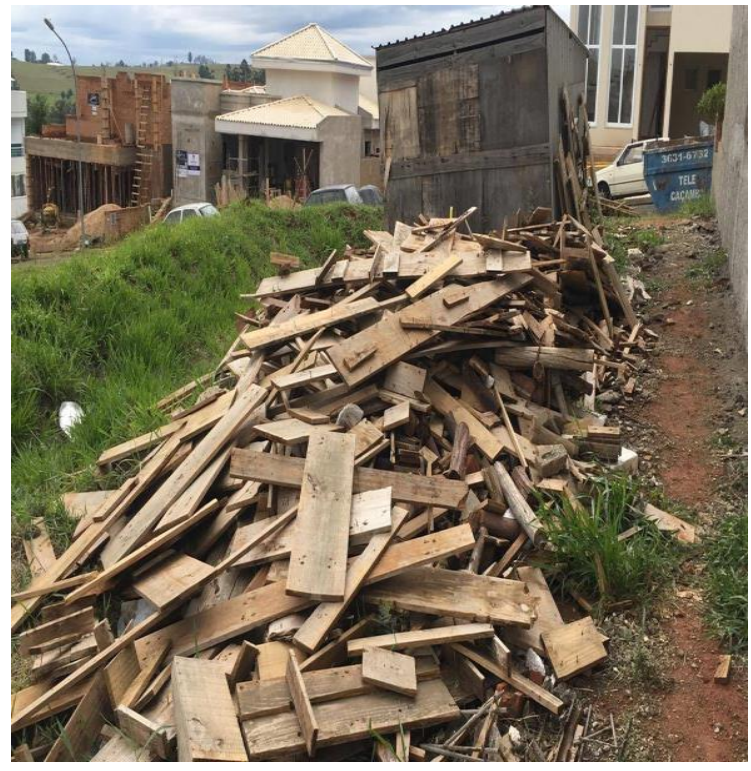

(b)

Fonte: Autores.

O gráfico 2 a seguir, monstra a variação no volume de resíduos encontrados no canteiro de obras, de acordo com as visitas periódicas, onde também é possível observar uma altenância na quantidade gerada, considerando-se o período internediário do estágio da obra.

Gráfico 2 - Comparação entre as diferentes visitas e quantidade de resíduos gerados, na obra na cidade de São José do Rio Pardo/SP

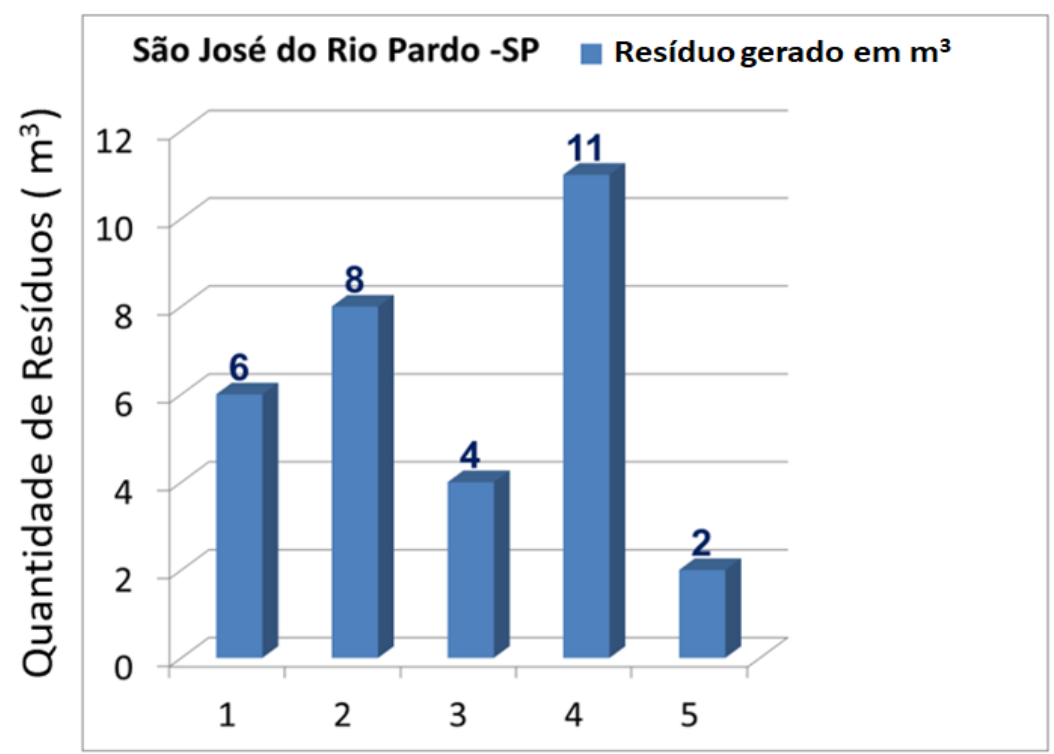

Número de visitas 
Foram observadas as quantidades de $6 \mathrm{~m}^{3}, 8 \mathrm{~m}^{3}, 4 \mathrm{~m}^{3}, 11 \mathrm{~m}^{3}$ e $2 \mathrm{~m}^{3}$, referentes a primeira, segunda, terceira, quarta e quinta visitas, respectivamente. A alternância nas quantidades de resíduos gerados está diretamente associada à fase em que se encontrava a obra e mesmo nessas condições, também não foram observadas separações adequadas quanto ao tipo de material, visando possível reaproveitamento do mesmo.

A forma como os resíduos foram dispostos nos terrenos (Figuras 4 e 5), considerando-se ambas as obras, constitue em ambiente propício para funcionar como esconderijo de animais peçonhentos e ratos, colocando em perigo a saúde da população, bem como os trabalhadores da obra, por estarem constantemente em contato com tal ambiente. Certamente o gerenciamento precário da obra, por parte dos responsáveis, e a falta de consciência ambiental, são fatores de extrema preocupação, uma vez que as implicações ambientais e de saúde pública são diretamente afetadas. Essa disposição inadequada dos resíduos e falta de gerenciamento, reforça o ponto conflitante entre desenvolvimento e preservação ambiental, carecendo de uma postura mais adequada e assertiva por parte de todos os envolvidos nos processos desde a planta, passando pela execução e finalização das obras.

\subsection{Avaliações e Correlações}

Para fins comparativos foi elaborado o gráfico 3 ilustrado a seguir, onde comparouse a quantidade de RCC gerados em ambas as obras em intervalos de tempo semelhantes, bem como na mesma fase intermediária de execução, onde na descrição, a obra 1 referese à cidade de Caconde e a obra 2 a cidade de São José do Rio Pardo.

De acordo com os resultados do gráfico 3 , pode-se concluir que no período avaliado e considerando-se a mesma fase intermediária em ambas as obras, a obra 2, gerou maior volume de resíduos nas visitas de 01, 03 e 04, enquanto que na obra 1, esta gerou maior quantidade de resíduos considerando-se a visita de número 05 , ao passo que na visita de número 02, equipararam-se os resultados. 
Gráfico 3 - Comparativo de dados coletados em ambas as obras analisadas

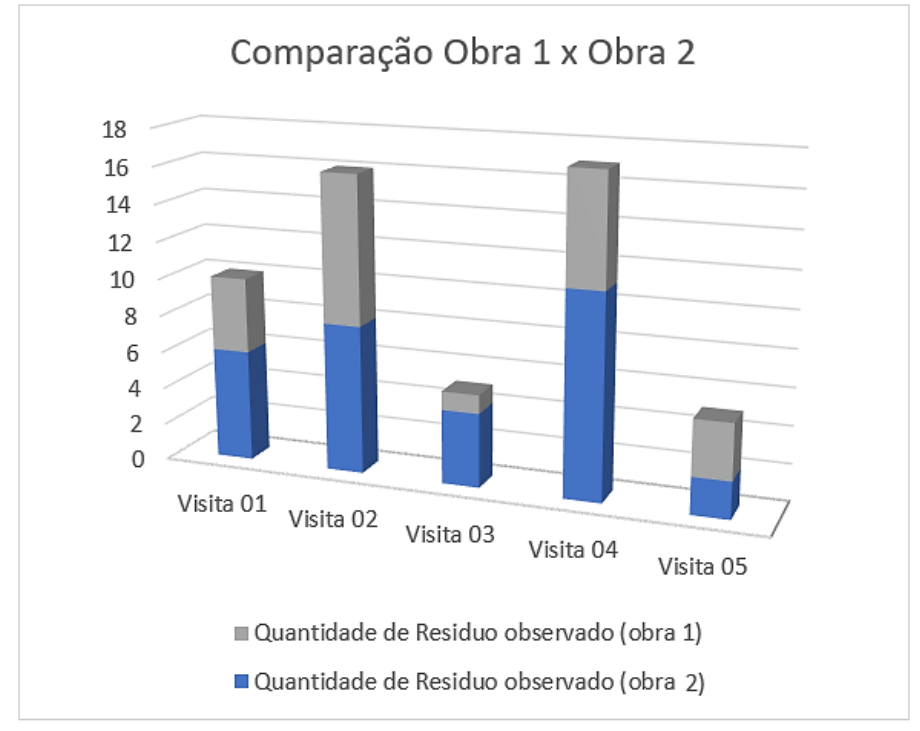

Considerando-se o método diagnóstico em canteiro de obras segundo Saurin e Formoso (2006), e correlacionando os dados do sistema de classificação para o canteiro de obras segundo o Ministério do Trabalho (Tabela 1), obteve-se os dados da tabela 5.

Tabela 5- Pontuação Possível (PP), Pontuação Obtida (PO), Índice de Grupo (lg) e Nota Global nos canteiros de obras

\begin{tabular}{|c|c|c|c|c|c|c|c|c|c|}
\hline \multicolumn{10}{|c|}{ Obra - Cidade de Caconde } \\
\hline \multirow{2}{*}{\multicolumn{3}{|c|}{$\begin{array}{c}\text { G1- Instalações } \\
\text { Provisórias }\end{array}$}} & \multirow{2}{*}{\multicolumn{3}{|c|}{$\begin{array}{c}\text { G2- Segurança na } \\
\text { Obra }\end{array}$}} & \multirow{2}{*}{\multicolumn{3}{|c|}{$\begin{array}{c}\text { G3- Movimentação } \\
\text { de materiais }\end{array}$}} & \multirow{3}{*}{$\begin{array}{l}\text { Nota Global do } \\
\text { Canteiro } \\
(P P+P O+\lg ) / 3\end{array}$} \\
\hline & & & & & & & & & \\
\hline PP & $\mathrm{PO}$ & $\lg$ & PP & PO & $\lg$ & PP & PO & $\lg$ & \\
\hline 23,00 & 5,00 & 2,17 & 17,00 & 11,00 & 6,47 & 27,00 & 21,00 & 7,70 & 5,44 \\
\hline \multicolumn{3}{|c|}{ Classificação: Ruim } & \multicolumn{3}{|c|}{ Classificação: Bom } & \multicolumn{3}{|c|}{ Classificação: Bom } & Classificação: Regular \\
\hline & \multicolumn{9}{|c|}{ Obra - Cidade de São José do Rio Pardo } \\
\hline PP & PO & $\lg$ & PP & $\mathrm{PO}$ & $\lg$ & PP & PO & $\lg$ & $(\mathrm{PP}+\mathrm{PO}+\mathrm{lg}) / 3$ \\
\hline 27,00 & 8,00 & 2,96 & 16,00 & 15,00 & 9,37 & 28,00 & 26,00 & 9,28 & 7,19 \\
\hline \multicolumn{3}{|c|}{ Classificação: Ruim } & \multicolumn{3}{|c|}{ Classificação: Ótimo } & \multicolumn{3}{|c|}{ Classificação: Ótimo } & Classificação: Bom \\
\hline
\end{tabular}

$\mathrm{Na}$ tabela 5, observa-se que para a cidade de Caconde/SP, e considerando-se o grupo1 (G1) de avaliações quanto às instalações provisórias da obra, esta apresentou $\mathrm{PP}=23,00$ pontos, $\mathrm{PO}=5,00$ pontos e um valor para o índice do grupo da ordem de 2,17 sendo, portanto, classificado como ruim. Para o grupo 2 (G2), eferente à segurança na obra a pontuação foi de $\mathrm{PP}=17,00$ pontos, $\mathrm{PO}=11,00$ pontos e $\lg =6,47$, sendo classificado como bom. Já os dados referentes ao grupo 3 (G3), movimentação de materiais, a pontuação foi 
para $\mathrm{PP}=27,00$ pontos, $\mathrm{PO}=21,00$ pontos e $\mathrm{Ig}=7,70$, sendo classificado como bom. A nota global do canteiro foi da ordem de 5,44, sendo classificado como regular.

Para a cidade de São José do Rio Pardo/SP, considerando-se o grupo1 (G1) de avaliações quanto às instalações provisórias da obra, esta apresentou $\mathrm{PP}=27,00$ pontos, $\mathrm{PO}=8,00$ pontos e um valor para o índice do grupo da ordem de 2,96, também sendo classificado como ruim. Para o grupo 2 (G2), a pontuação foi para o fator $P P=16,00$ pontos, $P O=15,00$ pontos e $\lg =9,37$, sendo classificado como ótimo. Já os dados referentes ao grupo 3 (G3), movimentação de materiais, a pontuação foi para o fator $P P=28,00$ pontos, $\mathrm{PO}=26,00$ pontos e $\mathrm{lg}=9,28$, sendo classificado como ótimo, onde a nota global do canteiro foi da ordem de 7,19 , sendo classificado como bom.

Em ambas as obras, as instalações provisórias, foram classificadas como ruins, sendo esta, atribuída à canteiros de obras que apresentam a maioria dos seus itens em desacordo com as normas regulamentadoras do trabalho, o que implica que em ambos os canteiros, são necessárias adequações, para manter o funcionamento das mesmas. Entretanto, como não há fiscalização, os trabalhos seguem o seu cronograma. Nas classificações "Regular", "Bom" e "Ótimo", a maioria dos itens do canteiro atendem aos requisitos mínimos das normas regulamentadores do trabalho, não acarretando em paralisações nas obras, sendo a classificação atribuída de acordo com o maior ou menor percentual de itens em acordo com os padrões mínimos para o funcionamento.

Comparando-se as notas obtidas para as diferentes obras, Gráfico 4 a seguir, observa-se que para a cidade de São José do Rio Pardo/SP, esta apresentou melhores resultados, para os grupos G2, G3 e G4, em comparação com os dados obtidos para a obra de Caconde/SP. Vale ressaltar que referente ao grupo G1, embora ambas as obras tenham sido classificadas como ruins, a de São José do Rio Pardo/SP, apresentou uma diferença para mais da ordem de 0,79 pontos. 
Gráfico 4 - Comparativo de dados coletados em ambas as obras analisadas, referentes aos grupos G1, G2, G3 e G4

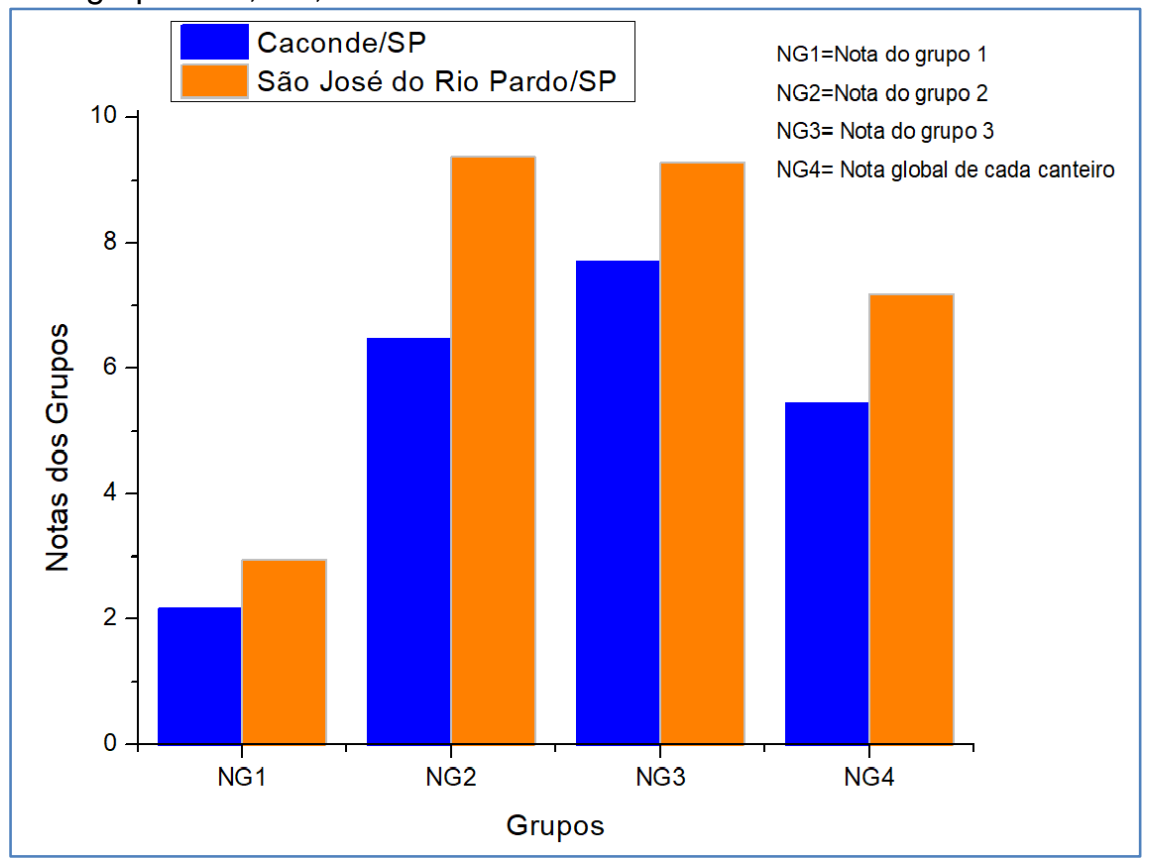

Destino dos resíduos da construção

Quanto a destinação dos RCC, foram contatadas as empresas do ramo, responsáveis pela retirada das caçambas, nas respectivas obras. No entanto, as empresas não manifestaram respostas quanto ao destino dos resíduos. Todavia os engenheiros das respectivas obras informaram que o principal destino destes resíduos são os aterros, onde não há nenhum tipo de processamento ou tratamento para descarte na natureza.

Segundo a ABRECON, Associação Brasileira para Reciclagem de Resíduos da Construção Civil e Demolição, aterros neste caso são definidos tal que a ideia central do aterro era a "reservação", ou seja, o recebimento, triagem e disposição do entulho numa área em tempo determinado. A reservação nada mais é do que, utilizar todo aquele material futuramente, assim como diz o texto da norma, "reservado para uso futuro". Em nenhum momento $o$ aterro de inertes foi concedido para destinação final, bem como, nunca $o$ aterro de inertes poderia receber resíduos que não fossem classe $A$, assim definido na resolução CONAMA no 307/2002, como sendo os resíduos cerâmicos (tijolos, blocos, telhas, placas de revestimentos, etc.), argamassa, concreto, dentre outros.

$\mathrm{O}$ aterro sanitário na cidade de Tapiratiba/SP, município próximo de ambas as cidades, é utilizado para descarte de resíduos urbanos, como consta em dados fornecidos pelo Tribunal de Contas do Estado (TCE, 2021), conforme descrito anteriormente. 
Entretanto, não foi possível confirmar se os municípios também utilizam esse mesmo aterro como depósito dos RCD gerados.

Segundo descrito no Plano Municipal de Gestão Integrada de Resíduos Sólidos da cidade de São José do Rio Pardo (GEOMA, 2016), os RCC são dispostos na mesma área de entreposto de galhos, localizada no Sítio Santa Maria, s/no, Zona Rural, conforme contrato administrativo no 09/2015, cujo objeto é a locação de área destinada para depósito de entulho e galhos, no valor de $\mathrm{R} \$ 1.900,00$ (um mil e novecentos reais) por mês. O mesmo documento descreve que a área serve de transbordo e triagem, sendo os resíduos Classe A, utilizados em calçamento de vias. No entanto, não foi informado se o local recebe apenas os RCC coletados pela prefeitura ou pelas empresas terceirizadas, nem qual a destinação final dos resíduos das demais classes. Atitudes como essas geram grande preocupação quanto ao destino adequado desses resíduos da construção em detrimento do meio ambiente, onde a falta de fiscalização por parte dos responsáveis e setor público, dos quais compete tal tarefa, implica certamente em procedimentos totalmente inadequados, havendo falta de consciência ambiental.

$\mathrm{Na}$ cidade de Caconde/SP a problemática é mais acentuada, pois não há um plano municipal nem o controle do sistema, e muito menos a fiscalização por parte do poder público. Considerando-se o total de resíduos gerados em ambas as obras, totalizando-se $53 \mathrm{~m}^{3}$ de resíduos, somente para essas duas obras analizadas, de fato, para comportar todo esse volume, seria necessária uma gleba de terra com $5,3 \mathrm{~m}$ por $12 \mathrm{~m}$ com uma profundidade de $1 \mathrm{~m}$, uma área consideravelmente alta se tratando de obras de pequeno porte em regiões interioranas.

Dessa forma, considerando-se os obras analisadas e toda a problemática relacionada à falta de gerenciamento por parte das construtoras e fiscalização por parte do poder público municipal, seria adequado que em ambas as localidades, houvesse um plano de ação específico para cada região, de forma a garantir o descarte adequado e a separação dos resíduos, visando o reaproveitamento.

A reciclagem no canteiro de obras, por exemplo, requer a condição inicial de que os resíduos gerados sejam da classe $A$ à qual nessa categoria se encontram sobras de concreto, argamassa, tijolos, blocos. Para tanto, existem duas formas para se iniciar o reaproveitamento dos materiais: a) estabelecer uma unidade de separação e tratamento no canteiro de obra, sendo necessário obter equipamentos móveis para se fazer a moagem e separação granulométrica e b) instalar usinas de reciclagem onde é realizada a triagem e a melhoria do material (SALOMÃO et al., 2019). 
Outra forma de gerenciamento que poderia ser viável em ambos os casos estudados, seria o uso do processo de logística reversa, que consiste em devolver à empresa que produz o material que seria descartado, para que a mesma reutilize em seus processos ou descarte de maneira adequada (DA SILVA et al., 2018), uma vez que ambos os municípíos não possuem local apropriado para o descarte, encaminhando seus resíduos em aterro localizado em um terceiro município. Sendo assim, seria possível usar a estratégia de gerenciamento, promovendo a prevenção qualitativa e quantitativa dentro dos processos. Qualitativa quanto a escolher materiais de fácil reciclagem e reutilização e, quantitativa em relação ao processo construtivo mais limpo, com menor utilização de recursos naturais e de menor geração de resíduos.

Além dessas alternativas, outras possíveis soluções que poderiam auxiliar no gerenciamento dos resíduos seriam: a existência de um órgão fiscalizador ativo para eficiência do processo de gestão; a educação ambiental atrelada à ideia de sustentabilidade; fomentar a indústria e a prática da reciclagem em ambos os municípios, bem como a identificação das falhas (SILVA et al., 2018) e o interesse por parte do poder público municipal, identificando possíveis melhorias. De fato, deve haver responsabilidade pública, privada e social, para que os resíduos gerados deixem de ser um problema.

\section{CONCLUSÕES}

O presente trabalho possibilitou avaliar a questão dos resíduos sólidos em obras de diferentes cidades do interior Paulista, na fase intermediária da construção. Constatou-se um total de $31 \mathrm{~m}^{3}$ coletados na obra de São José do Rio Pardo/SP, em comparação com $22 \mathrm{~m}^{3}$ da obra na cidade de Caconde/SP. Ambas as obras apresentaram classificação ruim para as instalações provisórias do canteiro de obras. Caconde/SP apresentou boa classificação quanto aos quesitos segurança na obra e movimentação de material, atingindo uma pontuação final de quesitos de monitoramento, enquadrado como sendo regular. A cidade de São José do Rio Pardo/SP, apresentou ótima classificação quanto aos quesitos segurança na obra e movimentação de material, atingindo uma pontuação final de quesitos de monitoramento, enquadrado como sendo bom.

Foi possível constatar que são geradas consideráveis quantidades de resíduos, seguidos de uma não seleção dos materiais, muitas vezes dispostos de forma inadequada no meio ambiente, havendo a necessidade de um monitoramento e fiscalização por parte 
do poder público, seleção adequada do material gerado, programas de reciclagem e reaproveitamento, logística reversa sendo estas, algumas das sugestões cabíveis, para ambos os municípios. Certamente grandes avanços ainda são necessários para que os municípios se enquadrem dentro de uma perspectiva aceitável no quesito, gestão ambiental e de acordo com as normas vigentes, principalmente a cidade de Caconde/SP que não possui uma legislação municipal, acerca do manuseio e destinação dos RCC e nem mesmo o monitoramento do que é gerado no próprio município.

$\mathrm{Na}$ tentativa de se alcançar melhorias à problemática identificada em ambos os municípios, as propostas sugeridas constituem em possíveis soluções que, se praticadas, certamente serão de grande contribuição para a eficiência dos processos, as quais estariam conciliando o desenvolvimento do setor construtivo, a adequação do manejo dos RCC e $R C D$, bem como ao desenvolvimento sustentável. Em ambas as cidades, os procedimentos realizados requerem maior atenção por parte das construtoras, que por sua vez carecem de fiscalização por parte do poder público, sendo necessário, portanto, maior rigidez dos orgãos competentes, bem como maior concientização em todas as esferas, quanto a sustentabilidade e a preservação ambiental.

\section{AGRADECIMENTOS}

Os autores agradecem a Universidade Paulista, Campus São José do Rio Pardo.

\section{REFERÊNCIAS}

ABRELPE. Associação Brasileira de Empresas de Limpeza Pública e Resíduos Especiais. Panorama dos resíduos sólidos no Brasil. 2017. 74p. Disponível em: http://abrelpe.org.br/download-panorama-2017/. Acesso em: 05 maio 2021.

BRASIL, Ministério do Trabalho. Programa de avaliações das condições de trabalho da indústria da construção civil. Metodologia Aplicada: check-List. Jundiaí - SP, 2003. Disponível em: http://www.fiocruz.br/biosseguranca/Bis/manuais/construca0\%20civil/Programa\%20de\%20Avaliac ao\%20das\%20Condicoes\%20de\%20Trabalho\%20da\%20Industria\%20da\%20Construca0\%20Civil .pdf . Acesso em: 24 jul. 2021.

BRASILEIRO, L. L.; MATOS, J. M. E. Revisão bibliográfica: reutilização de resíduos da construção e demolição na indústria da construção civil. Revista Cerâmica, v. 61, n. 358, p. 178-189, 2015. https://doi.org/10.1590/0366-69132015613581860

CIRELLI, A. S.; ZORDAN, S. E.; MOACYR, J. V. Desenvolvimento sustentável e a reciclagem de resíduos na construção civil. Disponível em: http://www.casoi.com.br/hir/pdfs/rdc.pdf Acesso em: 18 mar. 2021. 
CONAMA. Resolução 307/2002 do CONAMA. Disponível em:

http://www.mma.gov.br/port/conama/legiabre.cfm?codlegi=307. Acesso em: 05 jul. 2021.

CORONADO, M.; DOSAL, E.; COZ, JR V. ANDRE'S, A. Estimation of construction and demolition waste (C\&DW) generation and multicriteria analysis of C\&DW management alternatives: a case study in Spain. Waste Biomass Valorization, v. 2, n. 2, p. 209-225, 2011.

https://doi.org/10.1007/s12649-011-9064-8

DINÂMICA AMBIENTAL Reciclagem de madeira na construção civil. 2014. Disponível em: https://www.dinamicambiental.com.br/blog/reciclagem/reciclagem-madeira-solucao-sobrasconstrucao/ . Acesso em: 09 maio 2021.

FERNANDES, B. C. M. A utilização de resíduos da construção civil e demolição-RCD- como agregado para o concreto. Trabalho de Conclusão de Curso (Graduação) - Centro Universitário de Formiga, Formiga, MG 2015. 68 p.

FERREIRA, A. R. L.; HÉLINAH, C.M. Análise crítica da gestão de resíduos de construção civil: estudo de caso do município do Rio de Janeiro. Rio de Janeiro: UFRJ/ Escola Politécnica, 2013. VII, 129 p.: il.; $29,7 \mathrm{~cm}$.

FIEB. Gestão de resíduos na construção civil: Redução, reutilização e reciclagem. Livro publicado em parceria por COMPETIR; SENAI; SEBRAE; GTZ. 2021. Disponível em: http://www.fieb.org.br/Adm/Conteudo/uploads/Livro-Gestao-deResiduos id 177 xbc2901938cc24e5fb98ef2d11ba92fc3 2692013165855 .pdf . Acesso em: 21 maio 2021.

FROUFE, M. M.; MELLO, L. C. B. B.; SOARES, C. A. P. Indicadores de sustentabilidade em canteiros de obras, segundo o PBQP-h. Braz. J. of Develop., Curitiba, v. 6, n. 3, p. 10149-10163, mar. 2020. https://doi.org/10.34117/bjdv6n3-044

GEOMA AMBIENTAL Município de São José do Rio Pardo: Plano Municipal de Gestão Integrada de Resíduos Sólidos de São José do Rio Pardo, 2016. 290P.

GIL, A. C. Como elaborar projetos de pesquisa. 4. ed. São Paulo: Atlas, 2008.

GLÓRIA, M. V. A.; RIBEIRO JUNIOR, L. C.; SOUSA, F. H. F. Reciclagem e reutilização de resíduos da construção civil e demolição. Revista Científica Multidisciplinar Núcleo do Conhecimento. v. 11, n. 09, p. 61-80, nov. 2020.

https://doi.org/10.32749/nucleodoconhecimento.com.br/matematica/conjectura-de-beal

GOOGLEMAPS Disponível em: https://www.google.com.br/maps/ Acesso em: 02 maio 2021.

GRIGOLETTI, G. C.; SATTLER, M. A. Impactos ambientais associados a materiais de construção: análise de ferramentas existentes. In: NUTAU 2002 - Sustentabilidade, Arquitetura e Desenho Urbano, 2002. São Paulo. [Anais...]. São Paulo, SP: Universidade de São Paulo, 2002. p. 14091420.

IBGE. .Disponível em: https://cidades.ibge.gov.br/brasil/sp/caconde/panorama. 2010. Acesso em 08 mai 2021.

KALUARACHCHI, R. K. D. G. Analysis of Construction Waste Generation and Its Effect in a Construction Site. World Academy of Science, Engineering and Technology International Journal of Architectural and Environmental Engineering, v.12, n., 2018, p. 508-511. 
LAMÔNICA, C. H.; AZAMBUJA, M. A.; BATTISTELLE, R. A. G. Gestão dos Resíduos Sólidos da Construção Civil: um estudo bibliométrico na base Scopus e Web of Science (2009-2019). Revista Nacional de Gerenciamento de Cidades, v. 07, n. 51, 2019.

https://doi.org/10.17271/2318847275120192145

LEAL, A. P. Resíduos da construção civil: uma revisão sobre as possiblidadesde aplicação.

Revista Ibero-Americana de Humanidades, Ciências e Educação. São Paulo, v.7, n. 6. jun. 2021. https://doi.org/10.51891/rease.v7i6.1385

LIMA, R.S; LIMA, R.R.R. Resíduos Sólidos. Série de Cadernos Técnicos da Agenda Parlamentar, 2016. 36p. Paraná. Disponível em: http://www.crea-

pr.org.br/ws/wpcontent/uploads/2016/12/residuos-solidos.pdf .Acesso em:05 abr. 2021.

LIMA, A. R. O.; DE ALMEIDA, J. J. S. Impactos ambientais causados pelos resíduos da construção civil em Imperatriz-Maranhão, e publicado pela revista EA. Disponível em: http://www.revistaea.org/pf.php?idartigo=2119 . Acesso em: 09 jul. 2021.

MALTA, J. O.; SILVA, V. S.; GONÇALVES, J. P. Argamassa contendo agregado miúdo reciclado de resíduo de construção e demolição. Revista Eletrônica de Gestão e Tecnologias

Ambientais (GESTA), v. 1, n. 2, p. 176-188, 2013. https://doi.org/10.17565/gesta.v1i2.7214

MATUTI, B. B.; SANTANA, G. P. Reutilização de resíduos de construção civil e demolição na fabricação de tijolo cerâmico - uma revisão. Scientia Amazonia, v. 8, n.1, E1-E13, 2019.

NAGALLI, A. Gerenciamento de resíduos sólidos na construção civil. 1. ed. Paraná: Oficina de textos; 2014.

PAINEL TCE Disponível em:

https://painel.tce.sp.gov.br/pentaho/api/repos/\%3Apublic\%3ApainelSolidos\%3ApainelSolidos.wcdf/ generatedContent?userid=anony\&password=zero .Acesso em: 02 abr. 2021.

PNRS. Lei no 12.305, de 2 de agosto de 2010. Disponível em:

http://www.planalto.gov.br/ccivil 03/ ato2007-2010/2010/lei//12305.htm . Acesso em: 18 mar. 2021.

PROJETO DE LEI № 012/2019 DE 03/07/19. Disponível em: https://www.camaracaconde.sp.gov.br/novo site/processo legislativo/projetosdeleidoexecutivo/20 19/20190926081043.pdf . Acesso em: 05 jul 2021.

ROITMAN, F.; QUELHAS, O. L. G. Atributos de eco eficiência em projetos de Edificações públicas no Brasil. In: CONGRESSO NACIONAL DE EXCELÊNCIA EM GESTÃO, 11., 2015. [Anais...]. 13 e 14 de agosto de 2015. Disponível em :

https://www.inovarse.org/sites/default/files/T 15 361.pdf. Acesso em 16 nov. 2021.

SALOMÃO, P. E. A.; MALAGUTE, L. S.; LORENTZ, L. P. A.; DE PAULA, L. T. G. Reutilização dos resíduos gerados pela construção civil: uma breve revisão. Research, Society and

Development, v. 8, n. 10, p. 01-13, 2019. https://doi.org/10.33448/rsd-v8i10.1366

SANTOS, M. F. N.; BATTISTELLE, R. A. G.; HORI, C. Y.; JULIOTI, P. S. Importância da avaliação do ciclo de vida na análise de produtos: possíveis aplicações na construção civil. GEPROS -

Gestão da Produção, Operações e Sistemas, 2, p. 57, 2011.

SAURIN, T. A.; FORMOSO, C. T. Planejamento de Canteiros de Obra e Gestão de Processos. Recomendações Técnicas Habitare. v. 3. Porto Alegre. 2006. Disponível em:

http://cursos.unisanta.br/civil/arquivos/capítulos rt 3vol3-habitare.pdf. Acesso em: 01 abr. 2021. 
SEBRAE. Coleta seletiva e reciclagem de resíduos de madeira da construção civil, 2014. Disponível em: https://respostas.sebrae.com.br/coleta-seletiva-e-reciclagem-de-residuos-demadeira-da-construcao-civil/. Acesso em: 04 mai 2021.

SEBRAE. Panorama do setor de construção civil: cenários 2018-2020, 2019. Florianópolis- SC. Disponível em: https://atendimento.sebrae-sc.com.br/inteligencia/infografico/panorama-do-setorde-construcao-civil. Acesso em: 14 nov. 2021.

SCHMIDT, J. S.; OSEBOLD, R. Environmental management systems as a driver for sustainability: state of implementation, benefits and barriers in German construction companies. Journal of Civil Engineering and Management, v. 23, n.1, p.150-162, 2017.

https://doi.org/10.3846/13923730.2014.946441

SILVA, C. A.; SANTOS, G. R. Gestão de resíduos da construção civil e demolição responsabilidade pública, privada e social na cidade de São Paulo. Atas Saúde Ambiental, v.6, 2018, p.130 a 150. ISSN: 2357-7614.

SPADOTTO, A.; NORA, D. D.; TURELLA, E. C. L.; WERGENES, T. N.; BARBISAN, A. O. Impactos ambientais causados pela Construção civil. Unoesc \& Ciência - ACSA, Joaçaba, v. 2, n.2, jul. /dez. 2011, p. 173-180

SPCIDADES. Disponível em: http://spcidades.com.br/cidade.asp?codigo=113. 2021a. Acesso em: 20 jul 2021.

SPCIDADES. Disponível em: http://spcidades.com.br/cidade.asp?codigo=141 . 2021b. Acesso em: 20 jul 2021.

TORRES, L. De quem é o resíduo da construção? 2020. Disponível em:

https://www.temsustentavel.com.br/de-quem-e-o-residuo-da-construcao/ . Acesso em: 17 jul 2021. 